\title{
Synthetic Amphibian Peptides and Short Amino-Acids Derivatives Against Planktonic Cells and Mature Biofilm of Providencia stuartii Clinical Strains
}

\author{
KINGA OSTROWSKA ${ }^{1}$, WOJCIECH KAMYSZ ${ }^{2,3}$, MAŁGORZATA DAWGUL ${ }^{2}$ \\ and ANTONI RÓŻALSKI ${ }^{1}$ \\ ${ }^{1}$ Department of Immunobiology of Bacteria, Institute of Microbiology, Biotechnology and Immunology, \\ University of Łódź, Łódź, Poland \\ ${ }^{2}$ Department of Inorganic Chemistry, Faculty of Pharmacy, Medical University of Gdansk, Gdansk, Poland \\ ${ }^{3}$ Lipopharm.pl, Zblewo, Poland
}

Submitted 13 March 2014, revised 30 July 2014, accepted 15 September 2014

\begin{abstract}
Over the last decade, the growing number of multidrug resistant strains limits the use of many of the currently available chemotherapeutic agents. Furthermore, bacterial biofilm, due to its complex structure, constitutes an effective barrier to conventional antibiotics. The in vitro activities of naturally occurring peptide (Citropin 1.1), chemically engineered analogue (Pexiganan), newly-designed, short amino-acid derivatives (Pal-KK-NH $\mathrm{N}_{2}$, Pal-KKK-NH, Pal-RRR-NH ${ }_{2}$ ) and six clinically used antimicrobial agents (Gatifloxacin, Ampicilin, Cefotaxime, Ceftriaxone, Cefuroxime and Cefalexin) were investigated against planktonic cells and mature biofilm of multidrug-resistant Providencia stuartii strains, isolated from urological catheters. The MICs, MBCs values were determined by broth microdilution technique. Inhibition of biofilm formation by antimicrobial agents as well as biofilm susceptibility assay were tested using a surrogate model based on the Crystal Violet method. The antimicrobial activity of amino-acids derivatives and synthetic peptides was compared to that of clinically used antibiotics. For planktonic cells, MICs of peptides and antibiotics ranged between 1 and $256 \mu \mathrm{g} / \mathrm{ml}$ and 256 and $\geq 2048 \mu \mathrm{g} / \mathrm{ml}$, respectively. The MBCs values of Pexiganan, Citropin 1.1 and amino-acids derivatives were between 16 and $256 \mu \mathrm{g} / \mathrm{ml}, 64$ and $256 \mu \mathrm{g} / \mathrm{ml}$ and 16 and $512 \mu \mathrm{g} / \mathrm{ml}$, respectively. For clinically used antibiotics the MBCs values were above $2048 \mu \mathrm{g} / \mathrm{ml}$. All of the tested peptides and amino-acids derivatives, showed inhibitory activity against $P$. stuartii biofilm formation, in relation to their concentrations. Pexiganan and Citropin 1.1 in concentration range 32 and $256 \mu \mathrm{g} / \mathrm{ml}$ caused both strong and complete suppression of biofilm formation. None of the antibiotics caused complete inhibition of biofilm formation process. The biofilm susceptibility assay verified the extremely poor antibiofilm activity of conventional antibiotics compared to synthetic peptides. The obtained results showed that synthetic peptides are generally more potent and effective than clinically used antibiotics.
\end{abstract}

Key words: antimicrobial activity, antimicrobial peptides, bacterial biofilm, urinary tract infection

\section{Introduction}

Microbial biofilms are communities of microbes that adhere to various surfaces and are engaged in a self-produced extracellular matrix. Bacterial cells being a part of biofilm are physiologically distinct from planktonic cells and what is important, are embedded within a self-produced matrix of an extracellular polymeric substance, which can increase resistance to antibiotic, drugs and chemiotherapeutics even up to 1000 times (Park et al., 2011). It is estimated that over $60 \%$ of bacterial infections are associated with the phenomenon of biofilm formation (Giacometti et al., 2005; Hall-Stoodley and Stoodley, 2009).
This extremely unfavorable trend is particularly evident in the case of urinary tract infections (UTIs) which are the most common diagnosable chronic recurrent caused by bacterial microorganisms with an estimated annual worldwide incidence of nearly 250 million cases (Chapman and Rowland, 2014). The species composition of urinary pathogens is constantly changing, and the number of microorganisms recognized as etiological agents of UTI is steadily increasing. The use of analytical techniques such as molecular analysis of restriction fragment length polymorphism (T-RFLP), electrophoresis in denaturant gradient (DGGE), capillary electrophoresis or DNA sequencing in real time (pyrosequencing) allows a more complete description of the composition

* Corresponding author: K. Ostrowska, Department of Immunobiology of Bacteria, University of Łódź, Poland; e-mail: ostrowska. uni.lodz@wp.pl 
of pathogenic species in the urinary tract. The study of biofilms from internal urinary catheters showed the unusually frequent presence of P. stuartii (Ostrowska et al., 2013). These organisms are opportunistic pathogens responsible for nosocomial UTI, representing nearly $50 \%$ of all bacterial nosocomial infections and in over $30 \%$ of cases, being the cause of so-called urosepsis, leading to septic shock (Kupilas, 2010).

Antibiotic therapy is still the most common treatment for UTIs. Fluoroquinolones, nitrofurans, beta-lactams, aminoglycosides, trimethoprim and sulfonamides are used predominatingly (Ostrowska et al., 2013). However, biofilm, due to its complex structure, constitutes an effective barrier to the antibiotics used in the treatment of urinary tract infections. In addition, the growing number of multidrug resistant strains, limits the use of many of the currently available chemotherapeutic agents. The high resistance of $P$. stuartii clinical isolates to conventional antimicrobial agents has led us to seek alternative groups of antimicrobial compounds.

Antimicrobial peptides (AMPs) are unique molecules and have been identified in all living organisms (Dean et al., 2011; Żyłowska et al., 2011). They are considered to be endogenous antibiotics. The sequences and structures of antimicrobial peptides are incredibly diverse, but they share some common properties, like: amphiphatic secondary structures, small size, a net positive charge at neutral $\mathrm{pH}$, rapid binding to biological membranes, and what's extremely important, the ability to kill invading microorganisms within minutes (Mangoni et al., 2008; Pinheiro and Machado, 2012; Meng et al., 2011). It is estimated that the major targets of AMPs are intracellular molecules and cytoplasmic membrane of microorganisms (Park et al., 2011). The cationic character of AMPs allows for extremely strong interaction with negatively charged phospholipids of microbial membranes whilst the hydrophobic groups facilitate the penetration into the lipid phase of the microbial cell membrane, leading to membrane disruption (Cederlund et al., 2011; Baltzer and Brown, 2012). Natural antimicrobial properties of AMPs, their low propensity for the development of bacterial resistance, low toxicity, pace of action and unique mechanism of interaction with outer and inner bacterial membrane, make them a perfect alternative to conventional drugs in combating and preventing the formation of multidrug-resistant microorganisms (Baltzer and Brown, 2011; Cederlund et al., 2011; Park et al., 2011). Cationic peptides display antimicrobial activity against a wide range of bacteria, enveloped viruses, parasites and fungi (Baltzer and Brown, 2011; Ding et al., 2014). The results presented in this paper constitute the specific comparison of antimicrobial activity presented by peptides and conventional antibiotics, against both planktonic cells and mature biofilm of P. stuartii clinical strains.

\section{Experimental}

\section{Materials and Methods}

Antimicrobial agents. Antimicrobial Peptides: Compounds included in the study (Table I) were synthesized manually by the solid-phase method using the 9-fluorenylmethoxycarbonyl chemistry (Fmoc). The completeness of each coupling reaction was monitored by the chloranil test. The peptides were cleaved from the solid support by trifluoroacetic acid in the presence of water and triisopropylsilane. The cleaved peptides were precipitated with diethyl ether and were purified by high-performance liquid chromatography (HPLC) on a Knauer K501 two-pump system with Kromasil C8 column $10 \mathrm{~mm} \times 250 \mathrm{~mm}$ ( $5 \mu \mathrm{m}$ particle diameter, $100 \AA$ pore size) with a flow rate of $5 \mathrm{ml} / \mathrm{min}$ and gradient $20-50 \% \mathrm{~A} / 90 \mathrm{~min}$, absorbance at $226 \mathrm{~nm}$. The resulting fractions of purity greater than $95-98 \%$ were tested by HPLC (Kromasil C8 column, $4.6 \mathrm{~nm} \times$ $150 \mathrm{~nm}$ ). Compounds were analyzed also by matrixassisted laser desorption ionization-time of flight mass spectrometry (MALDI-TOF MS).

Table I

Amino acid sequences of obtained antimicrobial peptides and amino-acids derivatives ( $\mathrm{Pal}$ - palmitic acid residue)

\begin{tabular}{|l|l|}
\hline \multicolumn{1}{|c|}{ Peptide } & \multicolumn{1}{c|}{ Amino acid sequence } \\
\hline Citropin 1.1 & GLFDVIKKVASVIGGL-NH \\
\hline Pexiganan & GIGKFLKKAKKFGKAFVKILKK-NH \\
\hline Derivative 1 & Pal-KK-NH \\
\hline Derivative 2 & Pal-KKK-NH \\
\hline Derivative 3 & Pal-RRR-NH \\
\hline
\end{tabular}

Amino-acids derivatives were designed to imitate the properties of AMPs. The amphipathicity was achieved by combining fatty acid with the short peptide chain. The positive net charge of compounds results from the presence of basic amino acid residues.

Stock solutions $(1 \mathrm{mg} / \mathrm{ml})$ from dry powders were prepared fresh in physiological solution on the day of experiment and the concentration range assayed was between 1 and $512 \mu \mathrm{g} / \mathrm{ml}$.

Antibiotics. The following antibiotics were evaluated: amikacin, cefotaxime, cephalexin (all from SigmaAldrich, St. Louis, MO), cefepime and gatifloxacin (Bristol-Myers, Squibb Company, US). The Laboratory standard powders were diluted in accordance with manufacturers recommendations yielding $1 \mathrm{mg} / \mathrm{ml}$ solution. Stock solutions were prepared fresh in physiological solution on the day of experiment or stored at $-80^{\circ} \mathrm{C}$ until the time of used, but no longer than one week. The concentration range assayed was between 1 and $2048 \mu \mathrm{g} / \mathrm{ml}$. 
Table II

Data of the patients from which $P$. stuartii strains were isolated

\begin{tabular}{|c|c|c|c|c|c|}
\hline $\begin{array}{c}\text { P. stuartii } \\
\text { strain }\end{array}$ & $\begin{array}{c}\text { Catheteri- } \\
\text { zation time } \\
\text { [days] }\end{array}$ & Gender & Age & $\begin{array}{c}\text { Microbiological } \\
\text { examination/ } \\
\text { UTI }\end{array}$ & Affection/ treatment \\
\hline $\mathrm{C} 3$ & 21 & M & 79 & No/No & Prostatic hypertrophy/ rinsing with $3 \%$ boric acid \\
\hline $\mathrm{C} 7$ & 21 & $\mathrm{M}$ & 77 & $\mathrm{No} / \mathrm{No}$ & Prostatic hypertrophy/Oflodinex and rinsing with $3 \%$ boric acid \\
\hline $\mathrm{C} 9$ & 14 & $\mathrm{M}$ & 73 & Yes/Yes & Prostatic hypertrophy/Cipronex, Nevigramon and rinsing with 3\% boric acid \\
\hline C11 & 14 & $\mathrm{M}$ & 89 & No/No & Prostatic hypertrophy/ rinsing with $3 \%$ boric acid \\
\hline $\mathrm{C} 12$ & 17 & $\mathrm{M}$ & 73 & No/No & Prostatic hypertrophy/ rinsing with $3 \%$ boric acid \\
\hline $\mathrm{C} 13$ & 14 & M & 85 & No/No & Prostatic hypertrophy/ rinsing with 3\% boric acid \\
\hline $\mathrm{C} 15$ & 14 & M & 82 & No/No & Prostatic hypertrophy/ rinsing with 3\% boric acid \\
\hline $\mathrm{C} 18$ & 60 & M & 91 & No/No & Prostatic hypertrophy/Oflodinex and rinsing with 3\% boric acid \\
\hline C19 & 21 & M & 80 & No/No & Stroke \\
\hline $\mathrm{C} 24$ & 7 & M & 41 & No/No & Multiple sclerosis \\
\hline $\mathrm{C} 28$ & 12 & $\mathrm{M}$ & 85 & No/No & Spinal cord paralysis, ischemic heart disease and hypertension \\
\hline $\mathrm{C} 29$ & 5 & $\mathrm{M}$ & 83 & No/Yes & Prostatic hypertrophy, peptic ulcer disease/Cipronex \\
\hline C31 & 14 & M & 57 & No/Yes & Spinal cord injury and ventral urethral fistula paralysis/Nevigramon \\
\hline C33 & 21 & M & 88 & No/No & Prostatic hypertrophy, stroke, heart failure \\
\hline C37 & 14 & M & 79 & No/No & Prostatic hypertrophy, stroke \\
\hline C44 & 14 & M & 80 & No/No & Stroke \\
\hline C53 & 10 & M & 87 & No/No & Prostatic hypertrophy \\
\hline C55 & 14 & M & 86 & No/No & Prostatic hypertrophy \\
\hline C56 & 17 & M & 80 & No/No & Urinary retention \\
\hline $\mathrm{C} 85$ & 21 & M & 85 & No/No & Prostatic hypertrophy/ rinsing with 3\% boric acid \\
\hline
\end{tabular}

Bacterial strains A collection of 20 clinical strains of P. stuartii, were isolated from urological catheters derived from long-catheterized patients, from medical facilities in Lodz (Table II). Additionally as a quality control strain Escherichia coli ATCC25922 was used in the study.

MIC and MBC determination MICs of synthetic antimicrobial peptides, amino-acids derivatives and antibiotics were determined with the broth microdilution technique as described by the Clinical and Laboratory Standards Institute (CLSI) (CLSI, 2013). The MIC was defined as the lowest concentration of antimicrobial agent that produced complete inhibition of visible growth. The MBCs were determined at the end of the incubation process period by removing three $10-\mu \mathrm{l} \mathrm{sam-}$ ples from each well in which there was no visible growth of microorganisms and plating the aliquots onto TSA plate. Bacterial colonies were counted after 24 hours incubation at $37^{\circ} \mathrm{C}$. The $\mathrm{MBC}$ was defined as the lowest concentration of antimicrobial compound that produces $99.9 \%$ killing of the initial inoculum (Mataraci and Dosler, 2014). Concentration range of peptides used in the study was between 1 and $512 \mu \mathrm{g} / \mathrm{ml}$, and from 1 and $2048 \mu \mathrm{g} / \mathrm{ml}$ in the case of conventional antibiotics. Experiments were performed in triplicate.

Inhibition of biofilm formation. The Wakimoto method was adapted (Wakimoto et al., 2004; Chapman et al., 2014). The amount of $100 \mu$ l Müeller-Hinton (MH) medium was added to each well of a 96-well, type $\mathrm{F}$ plate. Exponential growth phase bacteria culture $(5 \mu \mathrm{l}$ of $1 \times 10^{5} \mathrm{CFU} / \mathrm{ml}$ ) was applied into each well of the plate, along with $100 \mu \mathrm{l}$ of antibiotic or antimicrobial peptide in appropriate concentration and then incubated for $18 \mathrm{~h}$ at $37^{\circ} \mathrm{C}$. After the incubation period, the medium was gently removed, and each well of the plates were washed four times with $150 \mu \mathrm{l}$ of sterile $\mathrm{dH}_{2} \mathrm{O}$ to remove unattached bacterial cells. Then $150 \mu \mathrm{l}$ of $0.5 \%$ Crystal Violet (CV) was added to each well, incubated for $5 \mathrm{~min}$. and discarded, next each well was rinsed gently with $200 \mu \mathrm{l}$ of $\mathrm{dH}_{2} \mathrm{O}$ and air dry. Biofilm was quantified at $595 \mathrm{~nm}$. The positive control were microorganisms in MH medium without antibiotic or peptide. The Crystal Violet assay is a widely used as a screening mechanism for biofilm formation process. The inhibition of biofilm formation is possible by observing a reduction of biofilm biomass when incubated with antimicrobial agents such as antibiotics or peptides.

Testing susceptibility of $P$. stuartii biofilm at antimicrobial compounds. Bacterial strains was cultured in $5 \mathrm{ml}$ of tryptic soy broth (TSB) with rotation (150 rpm), at $37^{\circ} \mathrm{C}$ for $24 \mathrm{~h}$, and diluted in fresh $\mathrm{MH}$ medium to a final density of $1 \times 10^{7} \mathrm{CFU} / \mathrm{ml} .100 \mu \mathrm{l}$ of this suspension was added to each well of a 96 -well polystyrene, type F microtiter plate and incubated for $24 \mathrm{~h}$ in $37^{\circ} \mathrm{C}$. 
After the incubation period, the medium was gently removed, and each well in the plates was washed four times with $150 \mu \mathrm{l}$ of sterile $\mathrm{dH}_{2} \mathrm{O}$ to remove unattached bacterial cells. In the next step $100 \mu$ lof a proper concentration of antimicrobial compounds was added per well and incubated for $24 \mathrm{~h}$ at $37^{\circ} \mathrm{C}$. The concentration range of antimicrobial peptides were between 1 and $1024 \mu \mathrm{l} / \mathrm{ml}$, and from 1 to $2048 \mu \mathrm{l} / \mathrm{ml}$ in the case of conventional antibiotics. After incubation period waste medium with antimicrobial agent were aspired and the wells of the plates were rinsed four times with $150 \mu \mathrm{l}$ of sterile $0.85 \%$ saline solution. The wells were stained with $100 \mu \mathrm{l}$ of $1 \% \mathrm{CV}$ (in water) for $5 \mathrm{~min}$. Excess dye was removed and each well was rinsed gently five times with $200 \mu$ l of sterile distilled water, and air dry. Next the stain was resolubilized in $100 \mu \mathrm{l}$ of $99 \%$ ethanol with shaking for $30 \mathrm{sec}$ and then the optical density was measured at $595 \mathrm{~nm}$ (Mataraci and Dosler, 2012). Untreated biofilms were used as positive controls were. Negative controls were only $100 \mu \mathrm{l}$ of $\mathrm{MH}$ broth, with no bacteria added. The intensity of the staining corresponding to the degree of biofilm formation. It was assumed that the absorbance value was directly proportional to the number of bacterial cells adhering to the surface of the plate (Chapman et al., 2014). Additionally staining with (3-(4,5-dimethylthiazol-2-yl)-2,5-diphenyltetrazolium bromide) (MTT) was performed (data not shown). Experiments were performed in triplicate.

Statistical analysis and evaluation. All experiments were analyzed in three independent assays. For the susceptibility testing of $P$. stuartii biofilm to antimicrobial compounds the results are shown as means \pm standard deviations of three independent experiments. A oneway analysis of variance with the Bonferroni multiple comparison test was used to compare the differences between antimicrobial-treated biofilms and untreated control. As a statistically significant a $P$ value of $<0.001$ was considered.

We define two levels of peptides suppression of biofilm formation and biomass eradication ability. A strong suppression/eradication was obtained if a peptide at a certain concentration, after adjusting for the negative control, caused $\geq 75 \%$ reduction of CV compared with the positive control. A complete suppression/eradication was obtained if a peptide at a certain concentration caused a reduction of $\mathrm{CV} \leq$ negative control value (Chapman et al., 2014).

\section{Results}

Despite the fact that antibiotics still remain a major line of treatment for bacterial infections we have shown that antimicrobial peptides are much more effective and show a stronger bactericidal and bacteriostatic effect than standard antibiotics.
The antibiotics commonly used in the therapy of urinary tract infection: amoxicillin + clavulanic acid, cefazolin, cephalexin, cefuroxime, cefaclor, ceftriaxone, cefotaxime, cefepime, gentamicin, amikacin, ciprofloxacin, ofloxacin, norfloxacin, cotrimoxazole, doxycycline and gatifloxacin, were tested against clinical strains of P. stuartii (data not shown). The most promising ones: gatifloxacin, cefepime, amikacin, ceftriaxone, cephalexin and cefuroxime, were selected for further study.

Susceptibility. The in vitro activities of the studied antimicrobial peptides, amino-acids derivatives and clinically used antibiotics against $P$. stuartii planktonic cells are summarized in Tables III and IV. The MIC values of the antibiotics against the quality control strain Escherichia coli ATCC25922 were within the accuracy range described by CLSI throughout the study (CLSI, 2013). We found that all of the planktonic P. stuartii cells (Tab. II) were resistant to all of the examined antibiotics, with MIC values ranging between 256 and $\geq 2048 \mu \mathrm{g} / \mathrm{ml}$ (Tab. III).

Although we noted a major difference between both inhibitory and bactericidal concentration of the antibiotics compared to antimicrobial peptides the MICs of the peptides were in general much lower than the MICs of the antibiotics. The most effective peptides were the synthetic analogue of magainin II Pexiganan and small, highly hydrophobic Citropin 1.1, both with MIC valueings ranged between 1 and $256 \mu \mathrm{g} / \mathrm{ml}$ (Tab. IV). Differences in the activity of antimicrobial peptides and conventional antibiotics were also observed by comparing bactericidal concentration values. The $\mathrm{MBC}$ values of antimicrobial peptides were generally equal or two times greater than the MIC values. The MBC values for the most active peptides Pexiganan and Citropin 1.1 were $\leq 256 \mu \mathrm{g} / \mathrm{m}$. Tangible results were also obtained for amino-acids derivatives where for Pal- $\mathrm{KKK}-\mathrm{NH}_{2}$ and $\mathrm{Pal}-\mathrm{RRR}-\mathrm{NH}_{2}$ for $80 \%$ of tested strains $\mathrm{MBC}$ values were equal to $256 \mu \mathrm{g} / \mathrm{ml}$, while in the case of conventionally used antibiotic $\mathrm{MBC}$ values were greater than the highest used concentration $(>2048 \mu \mathrm{g} / \mathrm{ml})$.

Inhibition of biofilm formation. All of the tested synthetic antimicrobial peptides and amino-acids derivatives, showed inhibitory activity against $P$. stuartii biofilm formation, in relation to their concentrations. The most active were synthetic peptides. With a few exceptions (P. stuartii C9, C19 and C56 strains) Pexiganan and Citropin 1.1 inhibit biofilm formation by all tested strains at concentrations around the MICs. Pexiganan and Citropin 1.1 in concentration range 32 and $256 \mu \mathrm{g} / \mathrm{ml}$ caused both strong and complete suppression of biofilm formation (Tab. V), while with antibiotics, a concentration range of often roughly $5-10 x$ MIC was needed to obtain a strong level of biofilm formation inhibition. None of the antibiotics caused complete inhibition of the biofilm formation process. 
Table III

The activity of conventional antibiotics used in the treatment of urinary tract infection

\begin{tabular}{|l|c|c|c|c|c|c|}
\hline \multirow{2}{*}{$\begin{array}{c}\text { P. stuartii } \\
\text { strain }\end{array}$} & \multicolumn{5}{|c|}{ Minimal Inhibitory Concentration (MIC), Minimal Bactericidal Concentration (MBC*) and values of antibiotics } \\
\cline { 2 - 7 } & Gatifloxacin & Amikacin & Cefepime & Cefalexin & Ceftriaxone & Cefotaxime \\
\hline C3 & 256 & 512 & 512 & $>2048$ & 256 & 256 \\
\hline C7 & 256 & 256 & 512 & $>2048$ & 1024 & 1024 \\
\hline C9 & 512 & 1024 & $>2048$ & $>2048$ & 2048 & 2048 \\
\hline C11 & 256 & 1024 & 2048 & $>2048$ & 1024 & 1024 \\
\hline C12 & 512 & $>2048$ & $>2048$ & 2048 & $>2048$ & $>2048$ \\
\hline C13 & 512 & 256 & 1024 & $>2048$ & 1024 & 1024 \\
\hline C15 & 256 & 512 & 1024 & $>2048$ & $>2048$ & $>2048$ \\
\hline C18 & 256 & $>2048$ & $>2048$ & $>2048$ & $>2048$ & $>2048$ \\
\hline C19 & 256 & $>2048$ & $>2048$ & $>2048$ & $>2048$ & $>2048$ \\
\hline C24 & 256 & 1024 & 512 & 2048 & $>2048$ & $>2048$ \\
\hline C28 & 1024 & 256 & $>2048$ & 2048 & $>2048$ & $>2048$ \\
\hline C29 & 512 & 1024 & $>2048$ & $>2048$ & $>2048$ & $>2048$ \\
\hline C31 & 1024 & $>2048$ & $>2048$ & $>2048$ & $>2048$ & $>2048$ \\
\hline C33 & 1024 & $>2048$ & $>2048$ & $>2048$ & $>2048$ & $>2048$ \\
\hline C37 & 512 & $>2048$ & $>2048$ & $>2048$ & 256 & 256 \\
\hline C44 & 256 & $>2048$ & $>2048$ & $>2048$ & $>2048$ & $>2048$ \\
\hline C53 & 512 & $>2048$ & $>2048$ & $>2048$ & $>2048$ & $>2048$ \\
\hline C55 & 512 & $>2048$ & $>2048$ & 2048 & $>2048$ & $>2048$ \\
\hline C56 & 1024 & 256 & 1024 & $>2048$ & 256 & 256 \\
\hline C85 & 256 & 512 & $>2048$ & 2048 & 256 & 256 \\
\hline
\end{tabular}

* MBC values in all case was above $2048 \mu \mathrm{g} / \mathrm{ml}$

Eradication of mature biofilm structure. Fig. 1 and Fig. 2 show the density of untreated and treated biofilm with Pexiganan in concentration 128 and $256 \mu \mathrm{g} / \mathrm{ml}$. Above all tested antimicrobial agents only Pexiganan in concentration $256 \mu \mathrm{g} / \mathrm{ml}$ was able to cause complete and strong reduction of biofilm biomass in the case of $5 \%$ and $80 \%$ of tested strains respectively. Moreover, Pexiganan in concentration $128 \mu \mathrm{g} / \mathrm{ml}$ caused strong reduction of biofilm density in $60 \%$ of all tested bacterial strains (Fig. 2). Citropin 1.1 caused strong reduction of biofilm biomass in the $60 \%$ of tested strains, only when applied in concentration $256 \mu \mathrm{g} / \mathrm{ml}$ (Fig. 3). For Pexiganan and Citropin 1.1 in concentration $256 \mu \mathrm{g} / \mathrm{ml}$ treatments $\mathrm{OD}_{595}$ ranged between 0.091 and 0.716 , and 0.193 and 1.134 , respectively against a control value between 0.878 and 3.206. Statistic analysis based on

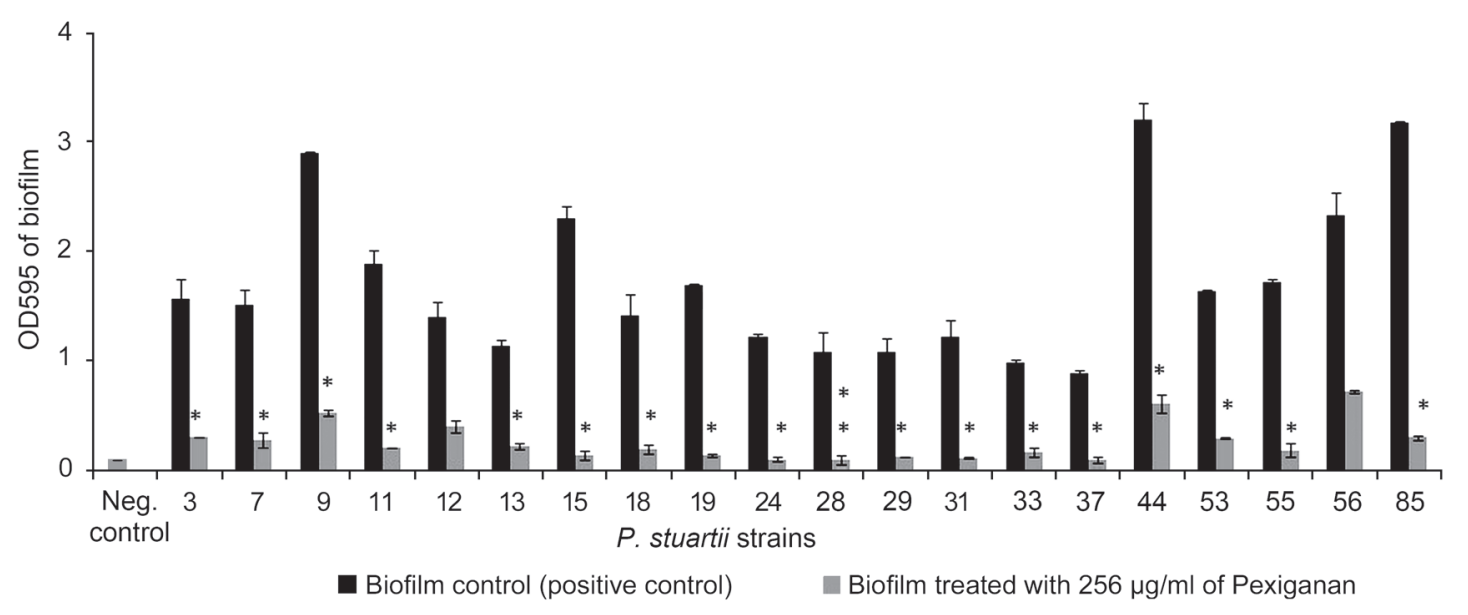

Fig. 1. Effect of $24 \mathrm{~h}$ treatment with $256 \mu \mathrm{g} / \mathrm{ml}$ of Pexiganan on $24 \mathrm{~h}$ biofilm of twenty P. stuartii clinical strains. Values are means of three experiments $+\mathrm{SD}$. ${ }^{\star}$ Strong reduction of biofilm biomass. ${ }^{* *}$ Complete eradication of biofilm. 
Table IV

The activity of antimicrobial peptides and amino-acids derivatives against clinical strains of $P$. stuartii

\begin{tabular}{|l|c|c|c|c|c|}
\hline \multirow{2}{*}{$\begin{array}{c}\text { P. stuartii } \\
\text { strain }\end{array}$} & \multicolumn{5}{|c|}{ Minimal Inhibitory Concentration (MIC) and Minimal Bactericidal Concentration (MBC) } \\
& Pexiganan & Citropin 1.1 & Pal-KK-NH & Pal-KKK-NH & Pal-RRR-NH $_{2}$ \\
\cline { 2 - 6 } & $8 / 32$ & $128 / 128$ & $256 / 256$ & $256 / 256$ & $128 / 215$ \\
\hline C3 & $8 / 16$ & $128 / 128$ & $256 / 512$ & $128 / 256$ & $128 / 256$ \\
\hline C7 & $128 / 256$ & $256 / 256$ & $128 / 256$ & $128 / 512$ & $128 / 256$ \\
\hline C9 & $1 / 16$ & $1 / 64$ & $1 / 16$ & $1 / 16$ & $2 / 16$ \\
\hline C11 & $256 / 256$ & $256 / 256$ & $128 / 256$ & $128 / 256$ & $128 / 256$ \\
\hline C12 & $8 / 128$ & $64 / 128$ & $128 / 256$ & $128 / 256$ & $128 / 256$ \\
\hline C13 & $32 / 256$ & $64 / 256$ & $128 / 128$ & $128 / 128$ & $128 / 256$ \\
\hline C15 & $4 / 16$ & $64 / 256$ & $128 / 256$ & $128 / 256$ & $128 / 256$ \\
\hline C18 & $128 / 256$ & $256 / 256$ & $256 / 256$ & $256 / 256$ & $128 / 256$ \\
\hline C19 & $32 / 256$ & $128 / 128$ & $256 / 256$ & $256 / 256$ & $256 / 256$ \\
\hline C24 & $256 / 256$ & $256 / 256$ & $256 / 512$ & $256 / 256$ & $256 / 512$ \\
\hline C28 & $256 / 256$ & $256 / 256$ & $256 / 256$ & $256 / 512$ & $256 / 256$ \\
\hline C29 & $64 / 256$ & $256 / 256$ & $256 / 256$ & $128 / 512$ & $256 / 256$ \\
\hline C31 & $32 / 128$ & $128 / 128$ & $256 / 512$ & $256 / 256$ & $256 / 256$ \\
\hline C33 & $128 / 256$ & $256 / 256$ & $256 / 256$ & $256 / 256$ & $256 / 256$ \\
\hline C37 & $64 / 256$ & $256 / 256$ & $256 / 256$ & $256 / 512$ & $256 / 512$ \\
\hline C44 & $16 / 128$ & $128 / 256$ & $256 / 512$ & $128 / 256$ & $64 / 512$ \\
\hline C53 & $16 / 256$ & $64 / 256$ & $256 / 256$ & $128 / 256$ & $64 / 512$ \\
\hline C55 & $128 / 256$ & $256 / 256$ & $256 / 256$ & $128 / 512$ & $256 / 512$ \\
\hline C56 & $128 / 128$ & $128 / 256$ & $128 / 512$ & $256 / 256$ & $256 / 256$ \\
\hline C85 & & & & \\
\hline
\end{tabular}

one-way analysis of variance with the Bonferroni test $(P$ value $<0.001)$ indicated that only Pexiganan at concentration $256 \mu \mathrm{g} / \mathrm{ml}$ was able to significantly eradicate 16/20 biofilms of P. stuartii. Analogous analysis for amino-acids derivatives showed no significantly abilities of these compounds in the eradication of biofilm structure. The biofilm susceptibility assay verified the extremely poor antibiofilm activity of conventional antibiotics compared to synthetic peptides.

\section{Discussion}

Nowadays the antibiofilm activities of antimicrobial agents are becoming an important part in treating biofilm-related infections, such as urinary tract infections or catheter associated infections caused by P. stuartii. In this study, we investigated the in vitro activities of clinically available antibiotic and synthetic antimicrobial peptides and amino-acids derivatives against $P$. stuartii

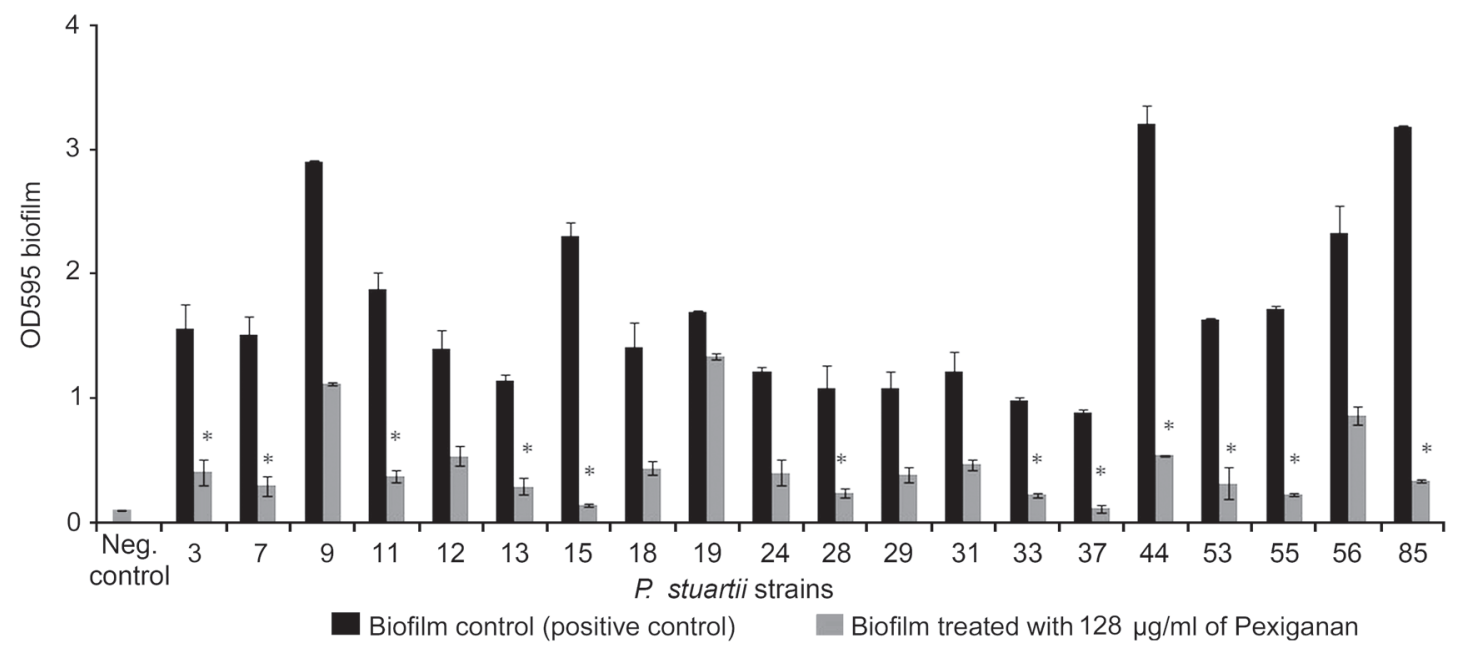

Fig. 2. Effect of $24 \mathrm{~h}$ treatment with $128 \mu \mathrm{g} / \mathrm{ml}$ of Pexiganan on $24 \mathrm{~h}$ biofilm of twenty P. stuartii clinical strains. Values are means of three experiments $+\mathrm{SD}$. ${ }^{*}$ Strong reduction of biofilm biomass. ${ }^{* *}$ Complete eradication of biofilm. 
Table V

Type of inhibition of biofilm formation process caused by peptides and amino-acids derivatives in their most active concentration range

\begin{tabular}{|c|c|c|c|c|c|c|c|c|}
\hline \multirow{3}{*}{$\begin{array}{c}\text { Percentage } \\
\text { of } \text { P. stuartii strains [\%] } \\
\text { Concentration }[\mu \mathrm{g} / \mathrm{ml}]\end{array}$} & \multicolumn{8}{|c|}{ Antimicrobial agent } \\
\hline & \multicolumn{4}{|c|}{ Strong suppression of biofilm formation ( $\geq 75 \%)$} & \multicolumn{4}{|c|}{$\begin{array}{l}\text { Complete suppression of biofilm formation } \\
\qquad(\geq \text { neg. control 0.091) }\end{array}$} \\
\hline & 256 & 128 & 64 & 32 & 256 & 128 & 64 & 32 \\
\hline Pexiganan & 50 & 50 & 60 & 65 & 40 & 20 & 10 & 10 \\
\hline Citropin 1.1 & 30 & 75 & 75 & 65 & 60 & 10 & 5 & 5 \\
\hline Derivative 1 & 20 & 15 & 10 & 10 & 10 & 5 & 5 & 5 \\
\hline Derivative 2 & 35 & 45 & 45 & 45 & 20 & 5 & 5 & 5 \\
\hline Derivative 3 & 35 & 40 & 45 & 40 & 35 & 10 & 5 & 5 \\
\hline
\end{tabular}

planktonic cells and mature biofilm. We found that planktonic cells of all tested P. stuartii clinical strains were highly resistant to conventional antibiotics used in the treatment of urinary tract infections caused by these microorganisms and demonstrating MIC values between 256 and $\geq 2048 \mu \mathrm{g} / \mathrm{ml}$. The most effective antibiotics were fourth-generation fluoroquinolones (gatifloksacin) and aminoglycosides (amikacin). Also, considering the ability of antibiotics to inhibit biofilm formation process we noted that the concentration range of these compounds required to cause strong inhibition of biofilm formation, was roughly 5-10x MIC. None of the antibiotics caused complete inhibition of the biofilm formation process. When we considered the antibiofilm activities of the tested antibiotics, concentration values were at least 10 fold times higher compared to MIC. The concentration ranges required by all the tested antibiotics to disrupt the biofilm formation process were too high to be used in therapy.

Antimicrobial peptides have the desirable properties to become excellent antimicrobial agents, and is this regard, they are considered one of the most promising antimicrobial substances for future use as medications for health-threatening and chronic infections (Mataraci and Dosler, 2012). The antimicrobial and antibiofilm activities presented by synthetic peptides and aminoacids derivatives used in our study were much stronger compared to antibiotics and demonstrated MIC values between 1 and $\geq 512 \mu \mathrm{g} / \mathrm{ml}$. The most active of the tested peptides against all tested P. stuartii strains were Pexiganan and Citropin 1.1 with MIC values ranging between 1 and $256 \mu \mathrm{g} / \mathrm{ml}$. Although, the MIC values of the synthetic peptides and amino-acids derivatives were not as low as we expected, it was notable that the peptides demonstrated greater antimicrobial activity than conventional antibiotics against P. stuartii clinical strains and that there were no very high MIC ratios, as seen with the antibiotics.

All of the tested synthetic antimicrobial peptides and amino-acids derivatives, showed inhibitory activity against $P$. stuartii biofilm formation, in relation to their concentrations. The most active were the synthetic peptides. With a few exceptions (P. stuartii C9, C19 and C56 strains) Pexiganan and Citropin 1.1 inhibited biofilm formation of all tested strains at concentrations around their MICs. Pexiganan and Citropin 1.1 in concentration range 32 and $256 \mu \mathrm{g} / \mathrm{ml}$ caused both strong and complete suppression of biofilm formation.

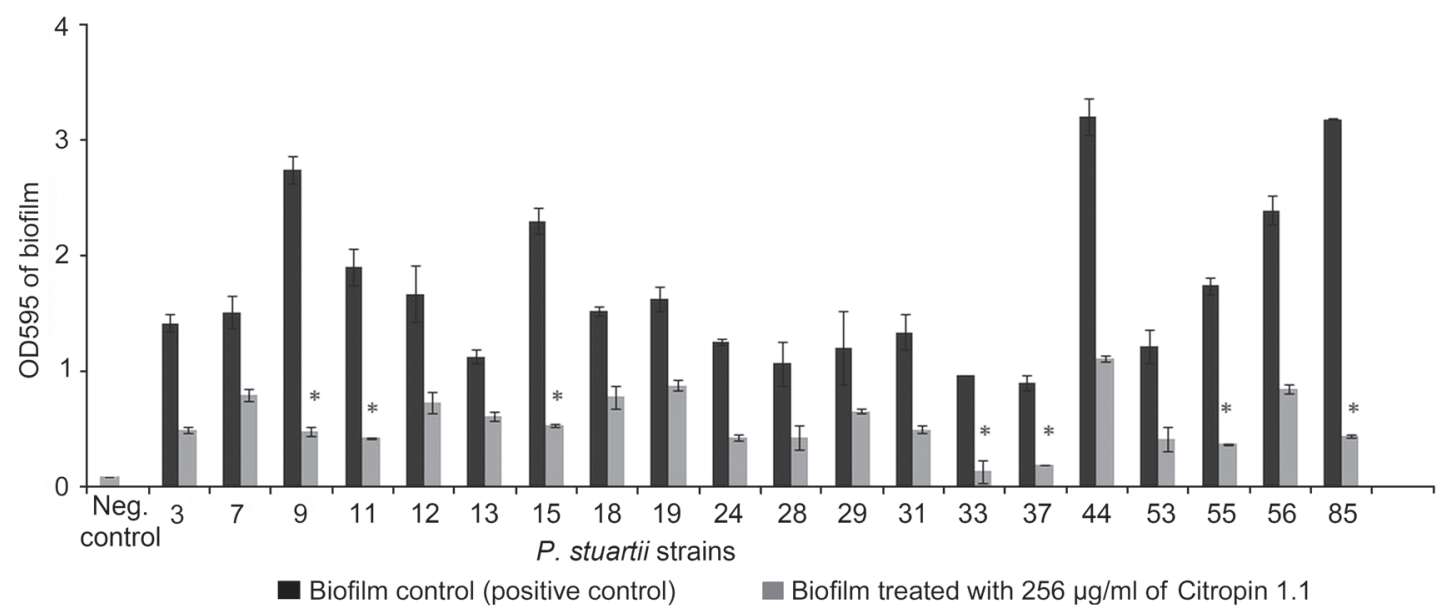

Fig. 3. Effect of $24 \mathrm{~h}$ treatment with $256 \mu \mathrm{g} / \mathrm{ml}$ of Citropin 1.1 on $24 \mathrm{~h}$ biofilm of twenty P. stuartii clinical strains. Values are means of three experiments $+\mathrm{SD}$. ${ }^{*}$ Strong reduction of biofilm biomass. ${ }^{* *}$ Complete eradication of biofilm. 
All of the tested synthetic antimicrobial peptides showed the ability to eradicate biofilm structure, but only Pexiganan in concentration $256 \mu \mathrm{g} / \mathrm{ml}$ was able to cause both, complete (5\% of strains) and strong $(80 \%$ of strains) reduction of biofilm biomass. Moreover, Pexiganan in concentration $128 \mu \mathrm{g} / \mathrm{ml}$ caused a strong reduction of biofilm density in $60 \%$ of all the tested bacterial strains. Citropin 1.1 caused a strong reduction of biofilm biomass in the $60 \%$ of tested strains, only at concentration $256 \mu \mathrm{g} / \mathrm{ml}$.

Statistic analysis showed that only Pexiganan in concentration 128 and $256 \mu \mathrm{g} / \mathrm{ml}$ was able to significantly eradicate biofilm structure in the case of $2 / 20$ and $16 / 20$ P. stuartii strains, respectively.

A major advantage of antimicrobial peptides is based on the principle of microbial cell membrane permeabilization. Peptides by binding to the components of the bacterial membrane, destabilize the structure of the lipid bilayer and inhibit the synthesis of membrane proteins (Cederlund et al., 2011; Mangoni et al., 2008; Gottler and Ramamoorthy, 2009; Lohner and Blondelle, 2005; Nicolas, 2009). Although the mechanisms inducing antibiotic-resistance are also diverse, the cellular action of antimicrobial peptides is separated from this mechanism. For that reason, antimicrobial peptides have the potential for use in a unique antibiotic drug for combating or preventing the formation of multidrug-resistant bacteria (Park et al., 2011; Flemming et al., 2009). Moreover, indisputable advantage of the endogenous peptide antibiotics in comparison to conventional antibiotics is the relatively low risk of the development of microbial resistance to these substances, as confirmed by in vitro studies (Zhang et al., 2005). Among these, is the composed of 22 amino acids Pexiganan also known as MSI - 78, an analogue of naturally occurring magainin II, extracted from the skin of the Xenopus laevis. Our results showed good in vitro activity of Pexiganan against both planktonic cell and mature biofilm of P. stuartii clinical strains. It is one of the AMPs with extremely high level of effectiveness and broad spectrum of activity. Pexiganan exerts its great antimicrobial activity to its ability to form toroidal pores in the bacterial membrane. The mechanism of cell membrane disruption by Pexiganan was confirmed by monitoring the leakage or uptake of fluorescent molecules from either E. coli or lipid vesicles. Pexiganan effectively induced the leakage of carboxyfluorescence from a model system for microbial cell membranes (POPC/POPG vesicles) as well as induced the uptake of ANS into E. coli cell membranes (Gottler and Ramamoorthy, 2009).

Due to its complex structure a bacterial biofilm constitutes an effective barrier to conventional antibiotics and also enhances antimicrobial resistance. An essential element that distinguishes planktonic cells from biofilm cells, and one of the key factors that gives biofilm sig- nificant resistance to antimicrobial agents are extracellular polymers forming a matrix surrounding the cells in a biofilm.

Microorganisms of the Providencia genus are opportunistic pathogens responsible for nosocomial urinary tract infections (UTI), representing nearly $50 \%$ of all bacterial nosocomial infections and in over $30 \%$ of cases, being the cause of the so-called urosepsis, leading to septic shock. P. stuartii has the capacity to colonize the surface of both tissues and implanted medical devices such as urological catheters made from such polymers as propylene, polystyrene, silicone, polyvinyl chloride or silicone latex. Obstruction of the urinary flow through the catheter may cause incontinence due to the leakage of urine around the catheter or painful distention of the bladder. Those microorganisms are the cause of many types of infections ranging from relatively minor inflammation of the bladder to the acute pyelonephritis, uremia and urological catheters stenosis, renal failure, or the formation of infectious urinary stones (Jiang et al., 2012). Pathological states caused by these microorganisms are recurrent and their therapy is extremely long and difficult.

However, treatment of infections caused by Gramnegative P. stuartii is additionally extremely difficult because of the presence of lipopolisaccharide (LPS) in the cell wall of these bacteria (Gruendheid and Moual, 2011; Gottler and Ramamoorthy, 2009). LPS consists the major structural component of the outer membrane in the case of Gram-negative bacteria and protects them from multiplicity factors, including AMPs. A huge number of conventional, clinically used antibiotics, lead to the release of LPS from the bacterial cell wall, which results in the secretion of pro-inflamatory cytokines (e.g. IL-6, TNFa or IL-6). In extreme cases this can lead to a harmful host response known as septic shock (Mangoni et al., 2008; Mukhopadhyay et al., 2004; Gee etal., 2003). However, AMPs are believed to have a potential as antibiofilm agents, due to their different mechanisms, which include functional inhibition of proteins, membrane-disrupting action, binding with DNA and most importantly detoxification of lipoteichoic acid and LPS (Park et al., 2011; Mangoni et al., 2008; Cohen, 2002).

Therefore, understanding the potential application of antimicrobial peptide in the treatment of bacterial infections is extremely important, especially in the case of Gram-negative microorganisms of the family Enterobacteriaceae, causing the most common infections affecting man during his life.

\section{Acknowledgements}

This work was funded by the University of Łódź research grant (No. 545/789) and supported by Operational Programme of Innovative Economy WND-POIG.01.04.00-22-052/11. 


\section{Literature}

Baltzer S.A. and M.H. Brown. 2011. Antimicrobial peptides - promising alternatives to conventional antibiotics. J. Mol. Microbiol. Biotechnol. 20: 228-235.

Cederlund A., G.H. Gudmundsson and B. Agerberth. 2011. Antimicrobial peptides important in innate immunity. FEBS Journal 278: 3942-3951.

Chapman C.M.C.,G.R. Gibson and I. Rowland. 2014. Effect of single- and multi-strain probiotics on biofilm formation and in vitro adhesion to bladder cells by urinary tract pathogens. Anaerobe, http://dx.doi.org/10.1016/j.anaerobe.2014.02.001.

Clinical and Laboratory Standard Institute (CLSI). 2013. Performance standards for antimicrobial susceptibility testing; Twentythird informational supplement M100-S23 (ISBN 1-56238-865-7 (M100-S23).

Cohen J. 2002. The immunopathogenesis of sepsis. Nature 420: 885-891.

Dean S.N., B.M. Bishop and M.L. Hoek. 2011. Natural and synthetic cathelicidin peptides with anti-microbial and anti-biofilm activity against Staphylococcus aureus. BMC Microbiology 11:114.

Ding Y., W.Wang, M. Fan, Z. Tong and R. Kuang. 2014. Antimicrobial and anti-biofilm effect of Bac8c on major bacteria associated with dental caries and Streptococcus mutans biofilms. Peptides 52: 61-67.

Flemming K., C. Klingenberg, J.P. Cavanagh, M. Sletteng M., W. Stensen, J.S. Svendsen and T. Flægstad. 2009. High in vitro antimicrobial activity of synthetic antimicrobial peptidomimetics against staphylococcal biofilm. J. Antimicrob. Chemother. 63: 136-145.

Gee K., M. Kozlowski and A. Cumar. 2003. Tumor necrosis factoralpha induces functionally active hyaluronan-adhesive CD44 by activating sialidase through p38 mitogen-activated protein kinase in lipopolysaccharide-stimulated human monocytic cells. J. Biol. Chem. 278: 37275-37287.

Giacometti A., O. Cirioni, W. Kamysz, C. Silvestri, A. Licci, A. Riva, J. Lukasiak and G. Scalise. 2005. In vitro activity of amphibian peptides alone and in combination with antimicrobial agents against multidrug-resistant pathogens isolated from surgical wound infection. Peptides 26: 2111-2116.

Gottler L. M. and A. Ramamoorthy. 2009. Structure, membrane orientation, mechanism and function of Pexiganan - a highly potent antimicrobial peptide designed from Magainin. Biochim. Biophys. Acta 1788(8): 1680-1686.

Gruenheid S. and H. Le Moual. 2012. Resistance to antimicrobial peptides in Gram-negative bacteria. FEMS Microbiol. Lett. 330: 81-89.
Hall-Stoodley L. and P. Stoodley . 2009. Evolving concepts in biofilm infections. Cellular Microbiology 11 (7): 1034-1043.

Jiang X., D. Abgottspon, S. Kleeb, S. Rabbani, M. Scharenberg, M. Wittwer, M. Haug, O. Schwardt and B. Ernst. 2012. Antiadhesion therapy for urinary tract infections a balanced PK/PD profile proved to be key for success. J. Med. Chem. 55 (10): 4700-4713.

Kupilas A. 2010. Przewlekłe zakażenia układu moczowego. Przegląd Urologiczny 5 (63).

Lohner K. and S.E. Blondelle. 2005. Molecular mechanisms of membrane perturbation by antimicrobial peptides and the use of biophysical studies in the design of novel peptide antibiotics. Comb. Chem. High Throughput Screen 8: 241-256.

Mangoni M.L., R.F. Epand, Y. Rosenfeld, A. Peleg, D. Barra, R.M. Epand and Y. Shai. 2008. Lipopolysaccharide, a key molecule involved in the synergism between Temporins in inhibiting bacterial growth and endotoxin neutralization. JBC 283(34): 22907-22917.

Mataraci E. and S. Dosler. 2012. In vitro activities of antibiotics and antimicrobial cationic peptides alone and in combination against methicillin-resistant Staphylococcus aureus biofilm. Antimicrob. Agents Chemother. 56(12): 6366-6371.

Meng S., H. Xu and F. Wang. 2011. Research advances of antimicrobial peptides and applications in food industry and agriculture. Curr. Protein Pept. Sci. 11(4): 264-273.

Mukhopadhyay S., J. Herre, G.D. Brown and S. Gordon. 2004. The potential for toll-like receptors to collaborate with other innate immune receptors. Immunology 112 (4): 521-530.

Nicolas P. 2009. Multifunctional host defence peptides: intracellular-targeting antimicrobial peptides. FEBS Journal 276: 6483-6496. Ostrowska K., A. Strzelczyk, A. Rozalski and P. Staczek. 2013. Bacterial biofilm as a cause of urinary tract infection - pathogens, methods of prevention and eradication. Postępy Hig. Med. Dosw. 67: 1027-1033.

Park S.Ch., Y. Park and K.S. Hahm. 2011. The role of antimicrobial peptides in preventing multidrug-resistant bacterial infections and biofilm formation. Int. J. Mol. Sci. (12): 5971-5992.

Pinheiro da Silva F. and M.C. Machado. 2012. Antimicrobial peptides: clinical relevance and therapeutic implications. Peptides 36(2): 308-314.

Wakimoto N., J. Nishi, J. Sheikh et al. 2004. Quantitative biofilm assay using a microtiter plate to screen for enteroaggregative Escherichia coli. Am. J. Trop. Med. Hyg. 71: 687-690.

Zhang L., J. Parente, S.M. Harris, D.E. Woods, R.E.W. Hancock and T.J. Falla. 2005. Antimicrobial peptide therapeutics for cystic fibrosis. Antimicrob. Agents Chemother. 49(7): 2921-2927.

Zyłowska M., A. Wyszynska and E.K. Jagusztyn-Krynicka. 2011. Defensyny - peptydy o aktywności przeciwbakteryjnej. Post. Mikrobiol. 5(3): 223-234. 
